\title{
SOSIALISASI PENTINGNYA KESADARAN MASYARAKAT TERHADAP LINGKUNGAN MELALUI KEGIATAN NETRALISASI SUNGAI
}

\author{
Ika Anggraheni ${ }^{1}$, Lailatul Mukarromah ${ }^{1}$, Novi Triani ${ }^{2}$, Mathari ${ }^{3}$, Ainun Nur Aziizi' ${ }^{\text {, }}$ \\ Lu'luul Millati Afifah', Refika Rahmawati4, Aldian Fajar Ismail ${ }^{3}$, M. Yusuf Alfan \\ Khoiruddin1, Baharudin Bessy3 ${ }^{3}$, Adelia ${ }^{2}$, Zulfa Mufarokhah', Muhammad Nizar \\ Abrory ${ }^{1}$ \\ ${ }^{1}$ Fakultas Agama Islam, Universitas Islam Malang \\ ${ }^{2}$ Fakultas Ekonomi dan Bisnis, Universitas Islam Malang \\ ${ }^{3}$ Fakultas Teknik, Universitas Islam Malang \\ ${ }^{4}$ Fakultas Keguruan dan Ilmu Pendidikan, Universitas Islam Malang \\ Korespondensi email: ika.anggraheni@unisma.ac.id
}

\begin{abstract}
ABSTRAK
Pemahaman sampah pada masyarakat masih sangat rendah. Hal ini seperti yang terjadi di desa Dadapan, Kecamatan Wajak, Kabupaten Malang. Persoalan pembuangan sampah yang tidak pada tempatnya sehingga menganggu kebersihan lingkungan terutama di Sungai Desa Dadapan. Secara umum kondisi alam desa Dadapan adalah perumahan yang penuh dengan bangunan rumah warga. Minimnya tempat pembuangan sampah membuat warga membuang sampah di sungai. Dalam permasalahan ini kami mengadakan program penetralisasi sungai. Kegitatan itu berupa pembersihan sungai yang telah tercemar oleh sampah masyarakat. Solusi dari pencemaran lingkungan tersebut diadakan program kelompok meliputi Pengadaan Tempat Sampah Untuk RT 015 RW 005 Dusun Pagar Gunung, Kerja Bakti, Sosialisasi Program KKN-PPM Tematik, Pendampingan TPA, Administrasi Desa.
\end{abstract}

Kata Kunci: kesadaran masyarakat; netralisasi sungai.

\section{PENDAHULUAN}

Pola hidup masyarakat Dadapan, terutama ditinjau dalam pola kebersihan masih kurang efektif dan efisien. Dalam survey di Dusun Dadapan ini kami menemukan banyak warga yang membuang sampah disungai. Dari hal tersebut, kita menyimpulkan untuk membuat inovasi baru dan cara baru agar masyarakat membuang sampah pada tempatnya (Elamin et al., 2018). Alasan masyarakat disini adalah tidak adanya tempat pembuangan sampah yang mewadahi. Sungai desa Dadapan sudah tercemar karena rata-rata warga mebuang sampah di sungai dengan alasan tidak ada TPA (tempat pembuangan sampah ahkir). Warga merasa membuang sampah di sungai merupakan cara membuang sampah yang efektif (Yulida et al., 2016) (Sulistiyorini et al., 2016). Dari permasalahan yang ada, adapun tujuan dari kegiatan kami yang pertama meningkatkan kesadaran masyarakat dalam menjaga kebersihan lingkungan. Kemudian menetralisir sungai yang telah tercermar oleh sampah masyarakat. Berikutnya memberikan sarana pembuangan sampah masyarakat Dusun Dadapan Rt.15 secara efesien dan efektif. Menciptakan suasana yang bersih dan nyaman. Kemudian mencegah dari penyakit, seperti Demam berdarah (Wilujeng \& Kusumandari, 2018). 
Sampah diartikan sebagai benda bersifat padat, tidak dipakai, tidak diinginkan dan dibuang. Kita masih banyak beranggapan bahwa sampah merupakan barang sepele dan membuangnya sesuka hati kita dimana saja kita berada (Yunik'ati et al., 2019) (Hamdan et al., 2018). Tidak jarang kita melihat pemakai jalan raya seenaknya membuang sampah di depan dagangan tanpa merasa risih. Di pinggir jalan terlihat tumpukan sampah yang menyerupai gunung kecil, terpencar-pencar. Di parit-parit juga terlihat penuh oleh bermacam-macam sampah. Dari kejadian seperti ini bisa dikatakan bahwa masyarakat belum menyadari bahwa sampah yang dibuang ini mempunyai dampak terhadap kesehatan masyarakat dan menimbulkan kekumuhan. Sehubung dengan hal diatas, maka Sholihah et al. (2019) mengatakan bahwa limbah padat merupakan salah satu bentuk limbah yang terdapat di lingkungan masyarakat, orang awam menyebutnya dengan sampah. Sampah dan kesehatan lingkungan sebenarnya hanya sebagian dari benda atau hal-hal yang dipandang tidak dapat digunakan lagi, tidak dipakai tidak disenangi, atau harus dibuang sedemikian rupa sehingga tidak sampai mengganggu kelangsungan hidup (Rhofita \& Chana AW, 2019).

\section{METODE}

Pelaksanaan KKN di Desa Dadapan dilaksanakan pada tanggal 01-29 februari 2020, Metode pelaksanaan yang di terapkan dalam pelaksanaan KKN PPM TEMATIK di RT 15 RW 05 di Desa Dadapan dimulai dengan Pembekalan, Survey, Pelatihan dan Pembinaan. Selain metode pelaksanaan adapun metode evaluasi pelaksanaan program kegiatan KKN ditinjau dari keberlangsungan program pada sasaran dari setiap program kerja dengan tahapan yaitu sosialisasi, netralisasi, dan pembuatan bak sampah.

\section{HASIL DAN PEMBAHASAN}

Kurangnya kesadaran masyarakat dadapan terhadap lingkungan dengan membuang sampah disaluran air dan sungai disekitarnya. Masalah sampah adalah masalah yang cukup serius bagi lingkungan, hal ini disebabkan karena hidup masyarakat yang serba praktis dan juga didukung oleh pola hidup yang konsumtif, sehingga mereka tidak dapat mengontrol penggunaan sampah. Maka dengan sosialisasi ini agar dapat menyadarkan masyrakat desa dadapan tentang bahaya nya sampah bagi kesehatan dan bagi lingkungan. Faktor yang mendukung sosialisasi, menetralisasi sungai dan pembuatan bak sampah ini dapat berjalan adalah bentuk kepedulian masyarakat sendiri akan pentingnya masalah sampah. Sehingga kedepannya dapat tercipta peningkatan kualitas masyarakat yang lebih baik. Diharapkan dengan adanya sosialisasi, menetralisasi sungai pembuatan bak sampah ini, kita dapat mengantisipasi dan meminimalisir dampak buruk yang ditimbulkan oleh sampah serta dapat merubah pola perilaku hidup kita akan jauh lebih baik dengan tahapan sebagai berikut:

1. Sosialisasi

Kegiatan ini kita bersosialisasi ke warga-warga untuk memberitahukan kegiatan atau program kerja kami di desa dadapan agar warga juga ikut berpartisipasi atau setidaknya membantu kegiatan kami didesa dadapan tersebut.

2. Netralisasi

Berhubung tercemarnya sungai maka dari itu kita melakukan netralisasi terhadap sungai agar tidak tercemar, adapun cara menetralisasi sungai kita melakukan pembersihan sungai dengan cara memungut sampah yang menyumbat di sungai.

3. Pembuatan Bak Sampah

Dengan adanya masyarakat yang membuang sampah sembarangan, kita mencoba melakukan pembuatan bak sampah untuk mengurangi pembuangan sampah di sungai- 
sungai agar masyarakat juga nyaman dengan lingkungan sekitar dan mencegah penyakit demam berdarah dan penyakit lainya.

Sampah merupakan suatu benda yang tidak ternilai bentuknya yang ada di lingkungan nanusia. Sampah dapat di artikan sebagai benda bersifat padat yang tidak di pakai dan tidak di gunakan dan di buang. Banyak yang beranggapan bahwa sampah merupakan barang yang sepele yang tidak kayak di gunakan. Tidak jarang kita melihat orang yang seenaknya membuang sampah sembarangan dan terlihat tumpukan sampah yang menyerupai gunung.

Di Indonesia dapat kami lihat sampah terdapat di mana mana khususnya di daerah perkotaan yang saat ini menjadi masalah terbesar dan serius dan hampir di semua kota di Indonesia mengalami kesulitan dalam hal mengelola sampah. Masyarakat Indonesia juga banyak yang membuang sampah ke selokan sungai, dan di lautan sehingga kebersihan dan ekosistem akan rusak. Pertimbangan Undang-undang nomer 18 tahun 2008 tentang pengelolaan sampah yang bertujuan untuk meningkatkan kesehatan menjadikan sampah sebagai sumber daya adalah:

1. Bahwa pertambahnya penduduk dan perubahan pola konsumsi masyarakat menimbulkan jenis dan karaktristik sampah yang semakin beragam.

2. Pengelolaan sampah saat ini belum sesuai dengan metode dan teknik pengelolaan smpah yang berwawasan lingkungan sehingga menimbulkan dampak negatif terhadap kesehatan lingkungan.

3. Sampah telah menajdi permasalahan nasional sehingga pengelolanya perlu di lakukan secara efektif.

Dapat di pahami dari di atas jumlah penduduk Indonesia yang besar dengan tingkat pertumbuhan yang tinggi mengakibatkan bertambahnya volume sampah. Di samping itu pola konsumsi masyarakat memberikan kontribusi dalam menimbulkan jenis sampah yang beragam. Sampai saat ini sebagaian besar masyarakat masih memandang sampah sebagai barang sisa yang tidak berguna bukan sebagai sumber daya yang perlu dimanfaatkan.

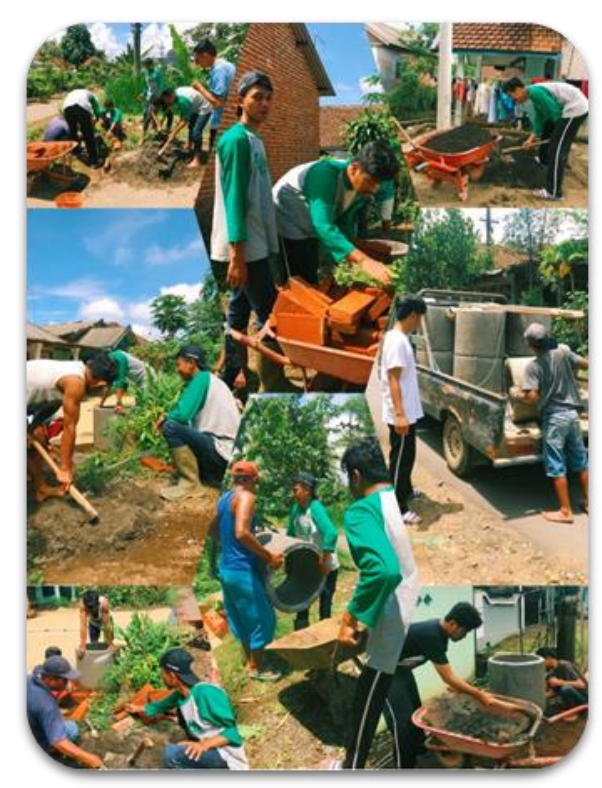

Gambar 1. Gambar pembuatan bak sampah dalam rangka solusi penetralisasi sungai

\section{KESIMPULAN}

Upaya memperbaiki taraf hidup masyarakat dusun pagar gunung desa dadapan kecamatan wajak kabupaten malang melalui sosialisasi pentingnya kesadaran masyarakat 
terhadap lingkungan melalui kegiatan-kegiatan netralisasi sungai, pembuatan bak sampah, dan pembakaran sampah.

Hal tersebut dikarenakan plastik merupakan bahan kimiawi artinya plastik bukanlah bahan yang alami, melainkan bahan buatan atau sintesis. Plastik-plastik yang telah menjadi sampah sulit untuk dikelola. Diperlukan waktu puluhan bahkan ratusan tahun untuk membuat sampah plastik itu benar-benar terurai. Namun yang menjadi persoalan adalah dampak negatif sampah plastik ternyata sebesar fungsinya juga.

Plastik jika digunakan tidak sesuai dengan fungsinya sangat berbahaya, jika dibuang tanpa adanya penanganan yang khusus pun berbahaya bagi lingkungan. Sampah plastik tidak dapat dibuang begitu saja ke tanah. Dibutuhkan waktu seratus tahun agar plastik dapat terurai oleh tanah secara terdekomposi atau terurai dengan sempurna. Ini adalah sebuah waktu yang sangat lama. Saat terurai, partikel-partikel plastik akan mencemari tanah, dan air tanah. Karena sifatnya yang sering terurai, sampah juga penyebab banjir, karena menyimbat saluran-saluran air, sehingga pada musim hujan tiba mengakibatkan banjir.

\section{DAFTAR RUJUKAN}

Elamin, M. Z., Ilmi, K. N., Tahrirah, T., Zarnuzi, Y. A., Suci, Y. C., Rahmawati, D. R., Dwi P., D. M., Kusumaardhani, R., Rohmawati, R. A., Bhagaskara, P. A., \& Nafisa, I. F. (2018). Analisis Pengelolaan Sampah Pada Masyarakat Desa Disanah Kecamatan Sreseh Kabupaten Sampang. Jurnal Kesehatan Lingkungan, 10(4), 368-375. https://doi.org/10.20473/jkl.v10i4.2018.368-375

Hamdan, Rifani, D. N., Jalaluddin, A. M., \& Rudiansyah. (2018). Pengelolaan sampah secara bersama: peran pemerintah dan kesadaran masyarakat. Jurnal Paradigma, 7(1), 4554. https://doi.org/10.30872/jp.v7i1.1885

Rhofita, E. I., \& Chana AW, L. (2019). Pemanfaatan Limbah Jerami Padi Di Desa Garon Kecamatan Balerejo, Kabupaten Madiun. Jurnal Inovasi Hasil Pengabdian Masyarakat (JIPEMAS), 2(2), 120-131. https://doi.org/10.33474/jipemas.v2i2.2915

Sholihah, F. A., Normaladewi, A., \& Laksono, P. T. (2019). Pengolahan Plastik Bekas Menjadi Bantal Hias Di Desa Ngempit Kecamatan Kraton Kabupaten Pasuruan. Jurnal Inovasi Hasil Pengabdian Masyarakat (JIPEMAS), 2(1), 9-17. https://doi.org/10.33474/jipemas.v2i1.1640

Sulistiyorini, N. R., Darwis, R. S., \& Gutama, A. S. (2016). Partisipasi Masyarakat Dalam Pengelolaan Sampah Di Lingkungan Margaluyu Kelurahan Cicurug. Share Social Work Jurnal, 5(1), 1-10. https://doi.org/10.24198/jppm.v3i3.13786

Wilujeng, B. S., \& Kusumandari, R. (2018). Gaya Hidup Bersih \& Antisipasi Demam Berdarah (DBD). Jurnal Abdikarya: Jurnal Karya Pengabdian Dosen Dan Mahasiswa, 1(1), 95-97. https://doi.org/10.30996/abdikarya.v1i1.2046

Yulida, N., Sarto, S., \& Suwarni, A. S. (2016). Perilaku masyarakat dalam membuang sampah di aliran sungai batang bakarek-karek Kota Padang Panjang Sumatera Barat (Community behavior in garbage disposal in Batang Bakarek-Karek river basin of Padang Panjang). Berita Kedokteran Masyarakat (BKM Journal of Community Medicine and Public Health), 32(10), 373-378. https://doi.org/10.22146/bkm.7298

Yunik'ati, Imam, R. M., Hariyadi, F., \& Choirotin, I. (2019). Sadar Pilah Sampah Dengan Konsep 4R (Reduce, Reuse, Recycle, Replace) Di Desa Gedongarum, Kanor, Bojonegoro. Jurnal Inovasi Hasil Pengabdian Masyarakat (JIPEMAS), 2(2), 81-87. https://doi.org/10.33474/jipemas.v2i2.1122 